\title{
Distribution of hospital beds across Saudi Arabia from 2015 to 2019: a cross-sectional study
}

Taghreed Hawsawi ${ }^{1}$ and Noura Abouammoh ${ }^{2}$

${ }^{1}$ Field Epidemiology Training Programme, Ministry of Health, Riyadh, Saudi Arabia. ${ }^{2}$ Department of Family and Community Medicine, College of Medicine, King Saud University, Riyadh, Saudi Arabia (Correspondence to: Noura Abouammoh: nabouammoh@ksu.edu.sa).

\begin{abstract}
Background: Adequate access to health care systems is considered a basic human right. Therefore, it is important that health care services be delivered to those who need them most in the most efficient manner possible.

Aims: We evaluated the distribution of hospital beds across Saudi Arabia from 2015 to 2019 to assess inequalities in hospital resource allocation.

Methods: This cross-sectional study utilized data from the Health Statistical Yearbook published by the Ministry of Health during the period 2015-2019. The number of hospital beds per 100000 population was calculated for the 20 health regions. Generation of other parameters, such as the Gini index and the Lorenz curve, was performed to assess the distribution of beds. The Pearson coefficient was calculated to assess the correlation between beds and population in each health region

Results: The ratio of hospital beds to population improved from 2015 to 2019 in areas such as Ha'il, Tabouk and Ta'if, which increased by 89.6, 72.5 and 32.5 respectively. The calculated mean Gini index for bed distribution in the public sector was 0.21 ; in the private sector it was 0.53 . There was a strong positive correlation between population and hospital beds in Riyadh, Qaseem, Eastern and Ha'il regions.

Conclusion: In Saudi Arabia the observed inequalities in hospital bed distributions lie mainly in the private sector. It is recommended that policymakers be aware of such inequalities and work on possible reforms to achieve the goals of Saudi Vision 2030.

Keywords: hospital beds, distribution, inequalities, resource allocation, Saudi Arabia

Citation: Hawsawi T; Abouammoh N. Distribution of hospital beds across Saudi Arabia from 2015 to 2019: a cross-sectional study. East Mediterr Health J. 2022;28(1):23-30. https://doi.org/10.26719/emhj.22.003

Received: $13 / 10 / 20$; accepted: $25 / 04 / 21$

Copyright $\odot$ W World Health Organization (WHO) 2022. Open Access. Some rights reserved. This work is available under the CC BY-NC-SA 3.0 IGO license (https://creativecommons.org/licenses/by-nc-sa/3.o/igo).
\end{abstract}

\section{Introduction}

Health is regarded as the main pillar of the development process among both human beings and civilization (1). Consequently, health care services are important for the promotion of overall fitness, prevention and management of diseases and reduction in avoidable health impairment and unnecessary fatalities. Consequently, equal and prompt access to health care services is a major concern and a fundamental element of many health policies, especially in developing countries $(2,3)$. It is therefore essential that governments distribute these resources fairly through their health care systems. However, allocation of resources is often influenced by political factors which override the actual needs of the population in certain regions (4). This highlights the need for evaluation of resource availability and equality across regions, which can subsequently promote solutions leading to a fair distribution of health resources (e.g. beds, personnel, medical apparatus) with the help of policymakers (5).

In Saudi Arabia, health services have improved exceptionally in the past 20 years as demonstrated by the increased availability of health resources throughout the country. Around $60 \%$ of the health services are sponsored by the Ministry of Health while the rest are shared between other governmental and private sectors (6), both subject to the regulations of the Ministry of Health. The improvements in health care delivery can partly be attributed to the contribution of the private sector to the health care system. In the 1980s, the budget deficit experienced by the Saudi Arabian economy led to the government's promotion of privatization of health care in the 1990s (7). The private sector then served as the main health care provider for workers of foreign descent while the Ministry of Health catered primarily to Saudi nationals. However, statistics from 1995 showed that an estimated $80 \%$ of the health care services provided by the private sector went to Saudi Arabian nationals even though they are eligible for the free health care services under the Ministry of Health (8). As of December 2018, 11 million beneficiaries are eligible to receive health care services from the private sector in the form of health insurance coverage (7).

Since the National Transformation Plan 2030 promotes rationalizing resource allocation between primary health care centres and hospitals (9), it is important to evaluate hospital bed distribution and optimize it according to population needs (10).

Similar studies from other countries have focused on the distribution of hospitals and hospital beds aiming to 
assess inequality in resource distribution applying the Gini index (11-14). This is a statistical variable commonly used to gauge income inequality in a specific population. It can also be used to estimate the degree of inequality in the allocation of other resources, in this case, health resources (15). Its numerical value can range from 0 to 1 as shown in Table 1 (15). In a Chinese study, for example, Gini index analysis revealed a spatial hospital bed clustering that disadvantaged western China, resulting in the region's lower average hospital bed resource availability (11). Another study conducted in 22 regions of Tehran province in the Islamic Republic of Iran calculated the Gini index of hospital bed distribution from 2010 to 2012 to be 0.46 , suggesting an unequal distribution across the province (12). Another Iranian study showed that $70 \%$ of the hospitals in 5 of its metropolitan cities were located in areas where the top $40 \%$ in terms of socioeconomic status reside (13). Assessing inequality according to the geographical distribution of the population is important to identify disadvantaged regions and help policymakers in making informed decisions regarding reallocation of services based on national health plans (14).

Saudi Arabia houses a population of over 34 million (16). The country provides services to 18 million visitors annually during the Hajj and Umrah periods. Achieving a balanced, adequate, and equality-based distribution and delivery of health resources, taking into account the geographic and demographic aspects, is one of the most challenging matters (17). A limited number of studies conducted in Saudi Arabia revealed inequalities in terms of accessibility of health services and resources. A study utilizing a geographic information system (GIS) evaluated the geographic variations in access to health services in Riyadh (18). The results showed significant clustering of health care facilities in central Riyadh compared with the marginal areas, where a considerable proportion of the population had to travel long distances to access public health care (18). In another study, the utilization of hospital beds in a university hospital in eastern Saudi Arabia was assessed to determine the efficiency in which the beds are being used (19). The mean occupancy rate of the hospital ranged from $30.9 \%$ to $77.0 \%$ and the observed underutilization of beds had implications on the equality of health resources when compared with other hospitals with limited resources (i.e. hospital beds) (19).

All in all, more research on the extent of inequalities in our health care system is needed, particularly in access and resource distribution. In the absence of evidence-

\begin{tabular}{ll}
\hline Table 1 Interpretation of Gini index values \\
\hline Gini index & Evaluation \\
$\leq 0.2$ & Perfect equality \\
$>0.2-0.3$ & Relative equality \\
$>0.3-0.4$ & Adequate equality \\
$>0.4-0.5$ & Large equality gap \\
$>0.5$ & Severe equality gap \\
\hline
\end{tabular}

based research covering this aspect, our study aims to investigate one indicator of regional inequality in health care delivery: hospital beds. This study evaluates the allocation of hospital beds across Saudi Arabia from 2015 to 2019 and examines the correlation and trends associated with it. Correspondingly, it will help policymakers to consider the potential redistribution of resources and maximize efficiency so that citizens and residents can further benefit from the health care system.

\section{Methods}

\section{Study design and setting}

This is a cross-sectional study was designed to evaluate hospital bed distribution among the 20 health regions of Saudi Arabia from 2015 to 2019. Secondary data collected by the Ministry of Health (i.e. number of beds per region, population per region, sociodemographics) were derived from the annually published Statistical Yearbook (16). All hospitals subject to the regulations of the Ministry of Health in the 20 health regions, including governmental and private hospitals, were covered in this study. We included in the calculations the whole population, both Saudi and non-Saudi, in the health regions.

\section{Tools and data extraction}

A Microsoft Excel 2016 spreadsheet was developed to extract the data (year, health region, population, hospital beds) from the Ministry of Health Statistical Yearbook (16). The number of hospital beds/100 ooo population in each of the 20 health regions was calculated for 20152019.

This study defines hospital beds in accordance to the World Health Organisation (WHO) definition, which describes a hospital bed as "a bed that is regularly maintained and staffed for the accommodation and fulltime care of a succession of inpatients and is situated in wards or a part of the hospital where continuous medical care for inpatients is provided" (20). This included both occupied and unoccupied beds in all hospitals, encompassing general hospitals and other specialty hospitals, including, but not limited to, rehabilitation, convalescence, eye, psychiatric, paediatric, obstetric, and gynaecology. Surgical tables, emergency stretchers, recovery trolleys, beds for same-day care, provisional and temporary beds, cots for healthy infants, and beds in nursing and residential care facilities were excluded (20).

\section{Statistical analysis}

The number of hospital beds for each region over the period of 2015-2019 was recorded. The "bed rate" was then estimated by calculating the number of hospital beds/100 ooo population as in the following equation (21).

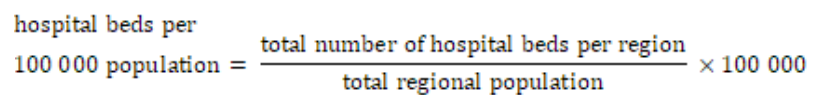

This variable is an important standardized indicator of health care accessibility, specifically of inpatient 
services, as it also allows comparisons within and among countries and regions.

The change in the health care service was analysed by calculating the rate of change in the total population and the rate of change in the total number of hospital beds in 2015 and 2019.

$$
P R=\frac{(\text { Vpresent }- \text { Vpast })}{\text { Vpast }} \times 100
$$

Where:

$\mathrm{PR}=$ percent rate

Vpresent $=$ present value

Vpast $=$ past value

To evaluate the equality in the geographical distribution of hospital beds among the health regions, the Gini index and the Lorenz curve were calculated and constructed using Excel, 2016. The Gini index is a statistical variable used in assessing inequalities (see Table 1). The Lorenz curve is a visual representation used to compare inequalities in reference to "perfect" equality. In the context of the study, the cumulative percentage of beds was represented on the y-axis and the cumulative percentage of population on the $\mathrm{x}$-axis (charts available on request). The chart also shows a diagonal straight line as a reference for perfect equality, and the Lorenz curve often lies below the straight line. The Gini index can also be calculated from the graph as it is the ratio between the area below the diagonal straight line and the curve to the overall area beneath the line of absolute equality (15).

To analyse the correlation between the changes in population and changes in number of hospital beds in each region from 2015-2019 we used SPSS, version 25, to calculate Pearson's correlation coefficient $(r)$. The correlation is significant at the 0.05 level.

\section{Results}

Table 2 shows the demographic characteristics of the Saudi Arabian population as of 2019. The total population was just over 34.2 million, with an annual growth rate of $2.4 \%$.

Data from the Health Statistical Yearbook form 2015 to 2019 were analysed, and descriptive statistics are shown in Table 3 (16). It can be seen that the general trend for number of beds and beds per 100000 population is increasing over time, although some fluctuations can also be observed. The total number of beds increased with population, from 3469 mean total beds for around 1576070 population in 2015 to 3849 mean total beds for approximately 1710908 population in 2019 in all the 20 health regions. The total bed rate improved from 237.0 in 2015 to 246.8 in 2019. Similar rate of change in the total population and the rate of change in the total number of hospital beds in the public sector, in 2015 and 2019. However, the total rate of change in both sectors was $10.9 \%$ as this was affected by the dramatic change in the number of beds in the private health sector (Table 4).

\begin{tabular}{|c|c|}
\hline Parameter & No. \\
\hline Total population & 34218169 \\
\hline \multicolumn{2}{|l|}{ Saudi population } \\
\hline Male & 10743666 \\
\hline Female & 10359532 \\
\hline \multicolumn{2}{|l|}{ Non-Saudi population } \\
\hline Male & 8995390 \\
\hline Female & 4119581 \\
\hline Annual population growth rate & 2.4 \\
\hline \multicolumn{2}{|l|}{ Age distribution (years) } \\
\hline$<5$ & 8.3 \\
\hline$<15$ & 24.5 \\
\hline $15-64$ & 72.3 \\
\hline$>64$ & 3.2 \\
\hline
\end{tabular}

The trend for hospital beds/100 000 population among the 20 health regions during 2015-2019 has been generally positive. A noticeable increase in the availability of hospital beds provided by the public sector was observed in Ha'il (from 171.3 to 253.7 beds/100 000 population), Tabouk (from 186.3 to 259.3 ) and Ta'if (from 222.7 to 257.3). For the private sector, a large increase was observed in Hafr Al-Baten (11.2 to 32.1), with smaller, but substantial, improvement in Ha'il (16.0 to 23.3) and Najran (25.8 to 41.1). The greatest improvement in overall bed rates was seen in the health regions of Ha'il (187.4 to 277.0), Tabouk (195.8 to 268.3) and Ta'if (260.7 to 293.2).

The Gini indices for the public and private sectors were calculated and these are summarized in Table 5. For the public sector, the Gini index hovers around 0.21, while the value is around 0.53 for the private sector. Considering both sectors, the overall Gini index for the 20 health regions is around 0.16 .

The Lorenz curve was constructed to demonstrate a visual representation of inequality in hospital bed distribution (charts for the Lorenz curves are available from the authors on request). The wider the gap between the equality line and Lorenz curve, the greater the inequality between the cumulative proportion of the population and the hospital bed rates. In the case of public sector-sponsored hospital beds, the Lorenz curves for 2015-2019 are almost the same and showed that $90 \%$ of the population had access to $60 \%$ of the hospital beds. For the private sector-sponsored hospital beds, the Lorenz curves for the same 5 years are also similar and all indicate that $90 \%$ of the population had access to only $27 \%$ of the hospital beds. Lastly, when both sectors are combined their Lorenz curves for the 5 years showed that $90 \%$ of the population had access to about $70 \%$ of the hospital beds.

The correlation between population and number of hospital beds for each region during 2015-2019 was 


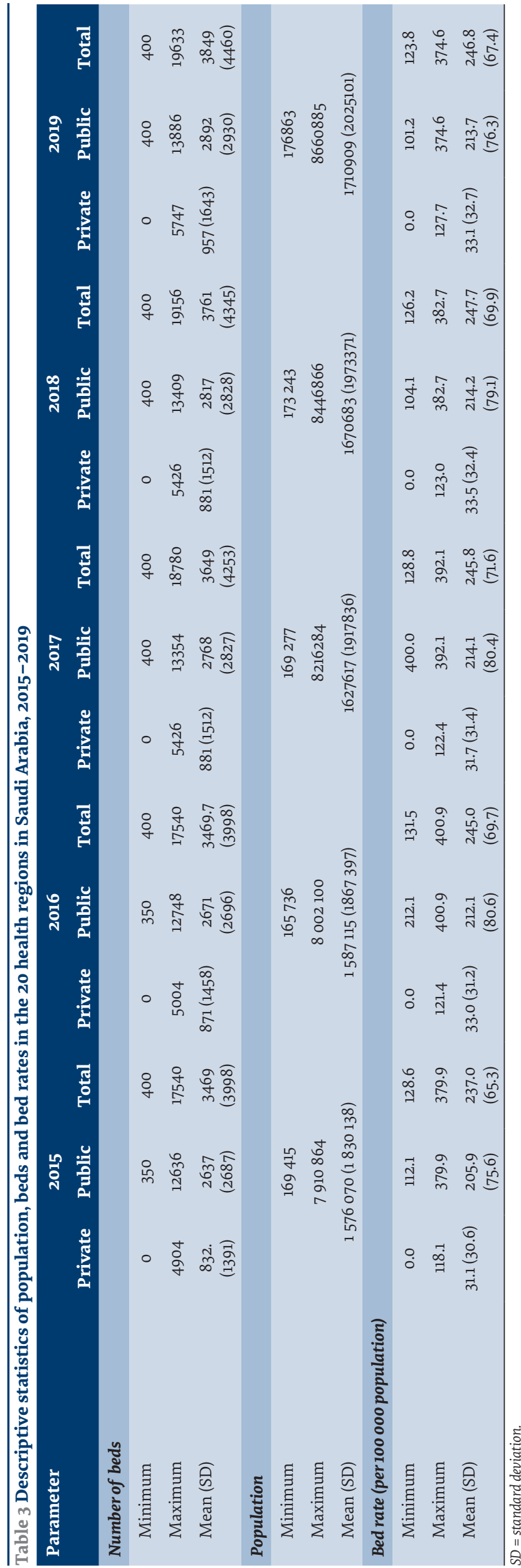

calculated. The Pearson correlation coefficient $r$ for public hospitals in the Riyadh, Qaseem, Eastern and Ha'il regions showed a strong positive correlation (Table 6). While, in Ta'if and Hafer Al-Baten regions the correlation was weakly positive. For Jazan, Albaha and Quryat regions the correlation was not applicable because the number of hospital beds did not change in the 5 years. The data for all regions combined showed a strong positive correlation (Table 6).

\section{Discussion}

This study was conducted to elucidate the current status of bed distribution among the 20 health regions in Saudi Arabia during 2015-2019 and to evaluate the equality in hospital bed distribution and its relationship with the population growth. This study assessed the adequacy and availability of health care services, especially inpatient services represented by bed numbers, for all populations in Saudi Arabia.

A general increasing trend was observed in the number of beds, in both public and private sectors. The increase in total bed rates per 100000 population across time is subtler, characterized by some fluctuations in values. This implies that there are small improvements in the ratio of hospital beds to population and that availability increased over time. A recent study assessed resource availability in the midst of the COVID-19 pandemic and showed that the global average among 183 countries under study was 307.1 hospital beds per 100000 population (22). In terms of income regions as designated by the World Bank, regions in the low-income category have a mean of 231.79 hospital beds/100 000 population; regions in the lower-middle-income category have a bed rate of 308.85; regions in the uppermiddle-income bracket have a bed rate of 283.13 , and high-income regions have 356.13 hospital beds/100 000 population (22). The World Bank classifies Saudi Arabia among the high-income regions (23), which means that we lag behind regional averages with our 2019 bed rate of 246.8. In comparison, the G20 countries have a mean rate of 450 beds/100 000 population (24). It is projected that there could be a gap of up to 40000 hospital beds by 2035 if no adjustments are made by the health sector (25). This could impact resource availability in Saudi Arabia, which may eventually lead to a deterioration in hospital services resulting in problems such as long patient waiting times (26). Interestingly, some countries have nationwide surplus of hospital beds, like Japan which

Table 4 Rate of change in total population and number of hospital beds in Saudi Arabia, 2015-2019

\begin{tabular}{lccc} 
Factor & $\mathbf{2 0 1 5}$ & $\mathbf{2 0 1 9}$ & \% change \\
Total population & 31521418 & 34218169 & 8.6 \\
Private hospital beds & 16648 & 19146 & 15.0 \\
Public hospital beds & 52746 & 57842 & 9.6 \\
Total hospital beds & 69394 & 76988 & 10.9 \\
\hline
\end{tabular}




\begin{tabular}{|c|c|c|c|c|c|c|c|c|}
\hline \multirow[t]{2}{*}{ Bed rate } & \multirow[b]{2}{*}{2015} & \multirow[b]{2}{*}{2016} & \multicolumn{3}{|l|}{ Year } & \multirow[t]{2}{*}{ Mean (SD) } & \multicolumn{2}{|c|}{$95 \% \mathrm{CI}$} \\
\hline & & & 2017 & 2018 & 2019 & & Lower & Upper \\
\hline Public sector & 0.205 & 0.215 & 0.213 & 0.211 & 0.206 & $0.210(0.004)$ & 0.205 & 0.215 \\
\hline Private sector & 0.532 & 0.517 & 0.538 & 0.534 & 0.539 & $0.532(0.009)$ & 0.521 & 0.543 \\
\hline Total & 0.158 & 0.164 & 0.169 & 0.164 & 0.158 & $0.163(0.005)$ & 0.157 & 0.168 \\
\hline
\end{tabular}

$\mathrm{SD}=$ standard deviation.

had an estimated 1223 beds per 100 ooo population in 2018 (13).

Among the 20 health regions, the greatest improvements in hospital bed rates were observed in Ha'il, Tabouk and Ta'if, owing primarily to investment in the public sector. However, these can also be attributed to the fact that some of these districts, specifically Tabouk, Ha'il and Najran, are characterized by small populations compared with other health regions. Some of the regions characterized by larger populations exhibit a fluctuating pattern due to the disproportionate increases in number of beds and population. It should also be noted that the public health sector has a greater impact on bed rates. This was also highlighted in a study analysing the timeline of health reforms in Saudi Arabia (27).
In terms of providing health care services, the contribution of the private sector is negligible compared with the share of the public sector. This is one of the reasons why the National Transformation Plan 2020 and the Saudi Vision 2030 prioritized developing the private sector through policy reforms to acquire more investment to improve the delivery of health care services to its citizens and residents (27).

No obvious trends were observed using Gini indices for both the public and private sectors across time. The public and private sector Gini indices showed good indicators of equality in the distribution of public sectorsponsored hospital beds among the 20 health regions. However, the Gini index for the private sector indicated a severe equality gap. There is clearly a need for assessment of the distribution of private sector-sponsored hospital

Table 6 Correlation between number of hospital beds in private and governmental hospitals and population for the 20 health regions in Saudi Arabia, 2015-2019

\begin{tabular}{|c|c|c|c|c|c|c|}
\hline Region & $r$ total & $\begin{array}{l}\text { Sig. } \\
\text { (2-tailed) }\end{array}$ & $\begin{array}{l}r \text { private } \\
\text { hospitals }\end{array}$ & $\begin{array}{c}\text { Sig. } \\
\text { (2-tailed) }\end{array}$ & $\begin{array}{c}\text { r public } \\
\text { hospitals }\end{array}$ & $\begin{array}{c}\text { Sig. } \\
\text { (2-tailed) }\end{array}$ \\
\hline Riyadh & 0.981 & 0.003 & 0.960 & 0.010 & 0.972 & 0.006 \\
\hline Makkah & 0.631 & 0.254 & NA & NA & 0.632 & 0.254 \\
\hline Jeddah & 0.914 & 0.030 & 0.822 & 0.088 & 0.716 & 0.174 \\
\hline Madinah & 0.779 & 0.120 & 0.903 & 0.036 & 0.687 & 0.200 \\
\hline Qaseem & 0.779 & 0.120 & -0.817 & 0.091 & 0.932 & 0.021 \\
\hline Eastern & 0.989 & 0.001 & 0.989 & 0.001 & 0.940 & 0.017 \\
\hline Asier & 0.766 & 0.131 & 0.155 & 0.804 & 0.627 & 0.258 \\
\hline Tabouk & 0.510 & 0.380 & NA & NA & 0.510 & 0.380 \\
\hline Ha'il & 0.967 & 0.007 & 0.958 & 0.010 & 0.965 & 0.008 \\
\hline Northern border & 0.662 & 0.224 & NA & NA & 0.662 & 0.224 \\
\hline Jazan & NA & NA & NA & NA & NA & NA \\
\hline Najran & 0.739 & 0.154 & 0.906 & 0.034 & 0.459 & 0.439 \\
\hline Al-Bahah & 0.916 & 0.029 & 0.916 & 0.029 & NA & NA \\
\hline Al-Jouf & 0.312 & 0.609 & NA & NA & 0.312 & 0.609 \\
\hline Qunfudah & NA & NA & -0.702 & 0.186 & 0.702 & 0.186 \\
\hline Quryat & NA & NA & NA & NA & NA & NA \\
\hline Besha & 0.784 & 0.116 & NA & NA & 0.784 & 0.116 \\
\hline Hafer Al-Baten & 0.410 & 0.493 & 0.210 & 0.734 & 0.890 & 0.043 \\
\hline Hassa & 0.912 & 0.031 & 0.920 & 0.027 & 0.843 & 0.073 \\
\hline Ta'if & 0.909 & 0.032 & NA & NA & 0.909 & 0.032 \\
\hline Total & 0.993 & 0.001 & 0.962 & 0.009 & 0.991 & 0.001 \\
\hline
\end{tabular}

Sig. = significance.

NA = not applicable.

Not applicable if the number of beds did not change over the 5 years.

Correlation is significant at the $\leq 0.05$ level (2-tailed). 
beds to deliver health care services efficiently and where they are needed. Overall, the mean Gini index across the 20 health regions for 2015-2019 falls under perfect equality. With more investments anticipated from the private sector due to policy reforms in the coming years, it is fair to expect that the Gini index for the private sector will improve over time (27).

The Lorenz curves also indicated a greater degree of inequality in terms of hospital bed distribution in the private sector. Furthermore, there are no obvious trends on the Lorenz curves for either sector over time. A study conducted in the Tehran province in the Islamic Republic of Iran used the Lorenz curve to illustrate the huge gap between "perfect equality" and the curve, which suggested unfair hospital bed distribution (12). Another Iranian study in 2014 found a Gini index of 0.68 for Shiraz, which suggested a severe equality gap, and the Lorenz curve constructed was far from the line of "perfect equality" (28).

This study was not without limitations. These included centralization of inpatient services, as outpatient services are not counted in this study. We were unable to make correlations with the degree of urbanization for each health region due to the lack of a reliable, complete and up-to-date source of urbanization data. The comparisons made between countries and regions based on hospital bed per 100000 population do not take into account differences in culture, values and other socioeconomic and sociodemographic factors, which may or may not affect the magnitude of such comparisons. Lastly, there could be inherent limitations in using secondary data. However, the data used for the study were from government institution and had been used to increase understanding of policymakers about the issue and to make informed decisions.

\section{Conclusion}

Saudi Arabia is lagging behind in terms of beds rate. More research should be conducted on the availability and allocation of resources per population and how these affect the efficiency of heath care delivery. Policymakers should pay close attention to the empirical data as these are needed to realize the Saudi Vision 2030 and to sustain the demands of the still-growing population of Saudi Arabia.

\section{Acknowledgement}

The authors are grateful to the Deanship of Scientific Research, King Saud University, for funding through the Vice Deanship of Scientific Research Chairs. We gratefully acknowledge the patients who participated in this study.

Funding: None

Competing interests: None declared.

\section{Répartition des lits d'hôpital en Arabie saoudite de 2015 à 2019 : étude transversale Résumé}

Contexte : L'accès adéquat aux systèmes de soins de santé est considéré comme un droit humain fondamental. Il est donc important que les services de soins de santé soient fournis de la manière la plus efficace possible à ceux qui en ont le plus besoin.

Objectifs: Nous avons évalué la répartition des lits d'hôpital dans toute l'Arabie saoudite de 2015 à 2019 pour mesurer les inégalités dans l'allocation des ressources hospitalières.

Méthodes: La présente étude transversale a utilisé les données de l'Annuaire des statistiques sanitaires publié par le ministère de la Santé au cours de la période 2015-2019. Le nombre de lits d'hôpital pour 100000 habitants a été calculé pour les 20 régions sanitaires. D'autres paramètres, tels que l'indice de Gini et la courbe de Lorenz, ont été générés pour évaluer la répartition des lits. Le coefficient de Pearson a été calculé pour évaluer la corrélation entre les lits et la population dans chaque région sanitaire.

Résultats : Le rapport entre le nombre de lits d'hôpital et la population s'est amélioré entre 2015 et 2019 dans des régions telles que Haïl, Tabouk et Taï, où il a augmenté de 89,6, 72,5 et 32,5 respectivement. L'indice de Gini moyen calculé pour la répartition des lits dans le secteur public était de 0,21; dans le secteur privé, il s'élevait à 0,53 . Il existe une forte corrélation positive entre la population et les lits d'hôpital dans les régions de Riyad, Al Qassim, Ach-Charqiya et Haïl.

Conclusion: En Arabie saoudite, les inégalités observées en matière de répartition des lits d'hôpital résident principalement dans le secteur privé. Il est recommandé que les décideurs politiques prennent conscience de ces inégalités et élaborent des réformes visant à atteindre les objectifs de la Vision 2030 saoudienne. 


\section{توزيع أسرَّة المستشفيات في أنحاء المملكة العربية السعودية من عام 2015 إلى عام 2019 20 : دراسة مقطعية تغريد هوساوي، نورا أبو أمامة}

الخلاصة

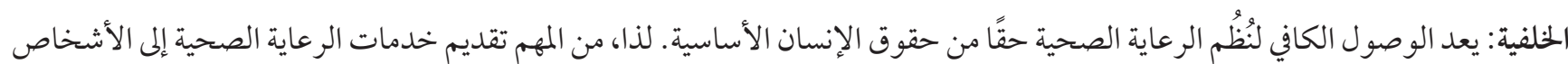

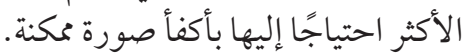

الأهداف: هدفت هذه الدر اسة إلى تقييم توزيع الأسرّة في المستشفيات على مستوى المملكة العربية السعودية في الفترة من عام 150 إلماتِ 20 إلى عام 2019

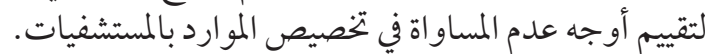

طرق البحث: استخدمت هذه الدراسة المقطعية بيانات من الكتاب السنوي للإحصاءات الصحية التي نشرتها وزارة الصحة خلاتل الفترة المترة 20 19190 20. وتم حساب عدد أسرَّة المستشفيات لكل

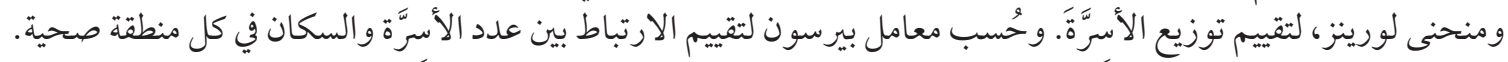

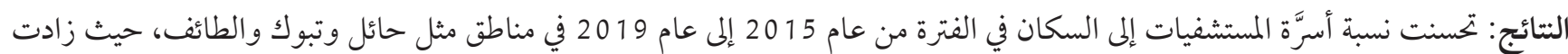

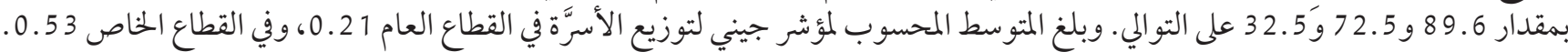

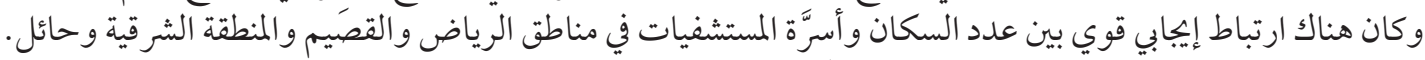

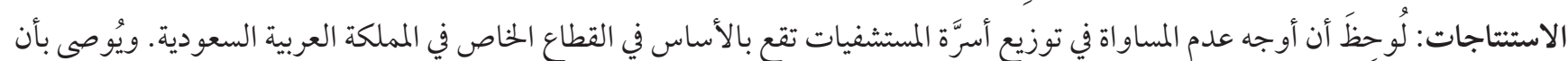

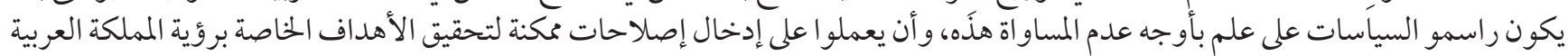
السعودية لعام 2030.

\section{References}

1. Institute of Medicine (US) Committee on Monitoring Access to Personal Health Care Services, Millman M, eds. Access to health care in America. Washington DC: National Academy of Sciences; 1993.

2. Access to health services. Rockville, Maryland: Office of Disease Prevention and Health Promotion; 2020 (https://www.healthyh people.gov/2020/topics-objectives/topic/Access-to-Health-Services, accessed 24 June 2021).

3. Shinjo D, Aramaki T. Geographic distribution of healthcare resources, healthcare service provision, and patient flow in Japan: a cross sectional study. Soc Sci Med. 2012 Dec;75(11):1954-63. doi:10.1016/j.socscimed.2012.07.032

4. Mobaraki H, Hassani A, Kashkalani T, Khalilnejad R, Chimeh EE. Equality in distribution of human resources: the case of Iran's Ministry of Health and Medical Education. Iran J Public Health. 2013 Jan 1;42(Suppl. 1):161-5. PMID: 23865035

5. Sebai ZA, Milaat WA, Al-Zulaibani AA. Health care services in Saudi Arabia: past, present and future. J Family Community Med. 2001 Sep;8(3):19-23. PMID: 23008647

6. Rahman R. The privatization of health care system in Saudi Arabia. Health Serv Insights. 2020 Jun 23;13:1178632920934497. doi:10.1177/1178632920934497

7. Walston S, Al-Harbi Y, Al-Omar B. The changing face of healthcare in Saudi Arabia. Ann Saudi Med. 2008 Jul-Aug;28(4):243-50. doi:10.5144/0256-4947.2008.243

8. Vision 2030: national transformation program. Kingdom of Saudi Arabia. (https://www.vision2030.gov.sa/en/programs/NTP, accessed 20 August 2020).

9. WHO country cooperation strategy at a glance: Saudi Arabia. Geneva: World Health Organization; 2017 (https://apps.who.int/ iris/handle/10665/136842, accessed 24 June 2021).

10. Pan J, Shallcross D. Geographic distribution of hospital beds throughout China: a county-level econometric analysis. Int J Equity Health. 2016 Nov 8;15(1):179. doi:10.1186/s12939-016-0467-9

11. Asl IM, Abolhallaje M, Raadabadi M, Nazari H, Nazari A, Salimi M, et al. Distribution of hospital beds in Tehran Province based on Gini coefficient and Lorenz curve from 2010 to 2012. Electron Physician. 2015 Dec 20;7(8):1653-7. doi:10.19082/1653. PMID: 26813480

12. Chavehpour Y, Rashidian A, Woldemichael A, Takian A. Inequality in geographical distribution of hospitals and hospital beds in densely populated metropolitan cities of Iran. BMC Health Serv Res. 2019 Aug 30;19(1):614. doi:10.1186/s12913-019-4443-0

13. Niga T, Mori M, Kawahara K. Relationship between regional population and healthcare delivery in Japan. J Med Dent Sci. 2016;63(1):9-18. doi:10.11480/jmds.630102

14. Bellù LG, Liberati P. Inequality analysis: The Gini Index; 2005 (http://www.fao.org/docs/up/easypol/329/gini_index_040en.pdf accessed 10 August 2020). 
15. Statistical yearbook. Riyadh: Ministry of Health; 2019 (https://www.moh.gov.sa/Ministry/Statistics/book/Pages/default.aspx, accessed 24 June 2021).

16. [National introductory guide for dentistry in the health sector.] Riyadh: Ministry of Health; 2020 (https://www.moh.gov.sa/ Ministry/MediaCenter/Publications/Documents/2018-11-01-010.pdf, accessed 24 June 2021) (in Arabic).

17. Mansour S. Spatial analysis of public health facilities in Riyadh Governorate, Saudi Arabia: a GIS-based study to assess geographic variations of service provision and accessibility. Geo Spatial Inform Sci. 2016;19(1):26-38.

18. Nour El Din MM. Bed utilization fluctuations at a university hospital in eastern Saudi Arabia and their impact on hospital cost. J Egypt Public Health Assoc. 2006;81(1-2):43-57. PMID: 17382083

19. Deputy Prime Minister. Definition and classification of hospital beds in nursing and residential care facilities. Valetta, Malta: Department of Health Information and Research; 2020 (https://deputyprimeminister.gov.mt//en/dhir/documents/definitions_ and_classifications.pdf, accessed 24 June 2021).

20. Monitoring the building blocks of health systems: a handbook of indicators and their measurement strategies. Geneva: World Health Organization.; 2010 (https://www.who.int/healthinfo/systems/WHO_MBHSS_2010_full_web.pdf, accessed 24 June 2021)

21. Sen-Crowe B, Sutherland M, McKenney M, Elkbuli A. A closer look into global hospital beds capacity and resource shortages during the COVID-19 pandemic. J Surg Res. 2021 Apr;260:56-63. doi:10.1016/j.jss.2020.11.062

22. World Bank country and lending groups Washington, DC: World Bank; (https://datahelpdesk.worldbank.org/knowledgebase/ articles/906519-world-bank-country-and-lending-groups, accessed 17 August 2020).

23. Hospital beds. Paris: Organisation for Economic Co-operation and Development; 2020 (https://data.oecd.org/healtheqt/hospital-beds.htm, accessed 4 August 2020).

24. Kumar G, Majdalani R, Jamal S. Healthcare in Saudi Arabia: opportunities in the sector. Riyadh: Knight Frank; 2018 (https://content.knightfrank.com/research/1526/documents/en/healthcare-in-saudi-arabia-opportunities-in-the-sector-may-2018-5563.pdf, accessed 24 June 2021).

25. Ewbank L, Thompson J, McKenna H, Anandaciva S. NHS hospital bed numbers: past, present, future. London: The King's Fund; 2017 (https://www.kingsfund.org.uk/publications/nhs-hospital-bed-numbers, accessed 24 June 2021).

26. Rahman R, Alsharqi OZ. What drove the health system reforms in the Kingdom of Saudi Arabia? An analysis. Int J Health Plann Manage. 2019 Jan;34(1):100-10. doi:10.1002/hpm.2584

27. Hatam N, Zakeri M, Sadeghi A, Darzi Ramandi S, Hayati R, Siavashi E. Equity analysis of hospital beds distribution in Shiraz, Iran 2014. Med J Islam Repub Iran. 2016 Jul 9;30:393. PMID: 27579284 